\title{
TRANSICIONES A LA DEMOCRACIA
}

Juan J. Linz*

Universidad de Yale

RESUMEN. Este artículo trata de los cambios de régimen que llevan a la democracia política, ocupándose exclusivamente del establecimiento y la consolidación de los regímenes democráticos que surgen de la transición desde regímenes autoritarios. El centro de atención son los regímenes no democráticos y no tradicionales y las características políticas e institucionales relacionadas con su desaparición, la probabilidad de las transiciones a la democracia y la consolidación de regímenes competitivos. El cuerpo del ensayo tiene los siguientes apartados: totalitarismo frente a autoritarismo, los regímenes sultanísticos, estabilidad e inestabilidad de los regímenes autoritarios, diez vías hacia la democracia, reforma o ruptura: un falso dilema, redemocratización y tipos de régimen, militares y democratización y consolidación democrática. En los años noventa en muchos países la apuesta más segura sobre el régimen político es que será una democracia. Este cuadro optimista no obstante se ve oscurecido por el hecho de que muy pocas democracias recientes están cerca de haberse consolidado.

Las recientes transiciones a la democracia que han triunfado en Europa, Iberoamérica y Asia han llevado a los estudiosos a centrar su interés en las transiciones de los regímenes políticos, los ingredientes del éxito en las transiciones y las perspectivas de democratización de países que aún no son democráticos. La esperanza y el deseo de promover la democratización han

* Juan J. Linz es Sterling Profesor de Ciencia Social y Política de la Universidad de Yale. Es coeditor con Larry Diamond y Seymour Martin Lipset de Democracy in developing Countries (Boulder, Colo.: Lynne Rienner Publishers, 1988 y 1989). 
motivado a algunos a usar con propósitos de ingeniería política el conocimiento adquirido, a fin de hacer avanzar la democracia. Hasta hace poco, lo que se sabía sobre los cambios de régimen se basaba principalmente en las investigaciones de los historiadores sobre las transformaciones que condujeron al nacimiento de las democracias modernas, así como sobre las crisis y quiebras de las democracias en Europa en el período entre las dos guerras ${ }^{1}$. Ahora hay cada vez más investigación académica sobre las crisis de regímenes no democráticos y las transiciones a la democracia o a las "inciertas democracias", por usar el título del importante trabajo de Guillermo O'Donell y Philippe C. Schmitter ${ }^{2}$.

\section{DEFINICION DEL TEMA}

Aunque hay muchos tipos de cambio de régimen, este artículo tratará sólo de aquellos que llevan a la democracia política. Incluso con este tema específico hay una gran variedad de categorías a explorar. Hay tantos tipos de regímenes democráticos como gobiernos democráticos hay en sociedades con diversos niveles de desarrollo económico y social, por no hablar de los diferentes grados en que los ideales de democracia política se convierten en realidad. Sin embargo, hay considerable acuerdo, o puede haberlo, sobre las características que definen un sistema político democrático ${ }^{3}$. Por otra parte, este ensayo se ocupará exclusivamente del establecimiento y la consolidación de los regímenes democráticos que surgen de la transición desde regimenes autoritarios. Esto excluye del análisis la lenta aparición de las instituciones políticas democráticas en Europa occidental y algunos de los

1 Juan J. Linz y Alfred Stepan (eds.), The Breakdown of Democratic Regimes, vols. 1, 2 y 3 (Baltimore: John Hopkins, 1978). Los tres volúmenes incluyen referencias a la literatura relevante. El vol. I está traducido con el título La quiebra de las democracias (Madrid: Alianza Editorial, 19...).

2 La referencia clásica es: Guillermo O'Donell, Philippe Schmitter y Laurence Whitehead (eds.), Transitions from Authoritarian Rule, Prospect for Democracy (Baltimore: John Hopkins, 1986). Véanse, también, Scott MaINwaring, Transitions to Democracy and Democratic Consolidation: Theoretical and Comparative Issues, Kellog Institute for International Studies, Working Paper 130 (Notre Dame, Ind.: University of Notre Dame, 1989); Guiseppe Di Palma y Laurence Whitehead (eds.), The Central American Impasse (Londres: Croom Helm, 1986); James Malloy y Mitchel Seligson (eds.), Autboritarians and Democrats: Regime Transition in Latin America (Pittsburgh: University of Pittsburgh Press, 1987); John H. Herz (ed.), From Dictatorship to Democracy, Coping with the Legacies of Authoritarianism and Totalitarianism (Wesport, Conn.: Greenwood, 1982) (véanse los capítulos sobre Alemania, Italia, Austria, Francia, Japón, España, Portugal y Grecia); Giuseppe Di Palma, To Craft Democracies. An Essay on Democratic Transitions (Berkeley: University of California Press, 1990).

3 No es posible entrar en el debate sobre las definiciones de democracia ni referirse a las contribuciones de Kelson, Schumpeter, Lipset, Dahl, ni al trabajo clásico de Sartori y sus críticos. Mi propio enfoque puede encontrarse en LINZ, La quiebra de las deomocracias, op. cit.; en mi contribución a Handbook of Political Science (véase infra) y en mi introducción a La Sociologia del partito politico, de Robert Michels (Bolonia: Il Mulino, 1960). 
fragmentos de sociedades europeas allende los mares, comenzando en el siglo XVIII, que constituyen el pequeño grupo de democracias continuas y estables que no han experimentado quiebra alguna en sus instituciones políticas desde que se instauraron.

Puede aprenderse mucho del largo y complejo proceso de desarrollo de las instituciones democráticas, desde los estados absolutos a las monarquías constitucionales, y del proceso más o menos continuo de creciente democratización. Sería un error, sin embargo, pensar que cualquier sociedad podría seguir hoy el camino que llevó a la democracia en el Reino Unido, Suecia, los Estados Unidos o Suiza. Las sociedades contemporáneas deben concentrar ese largo proceso histórico en unos pocos años críticos, y el contexto social, económico, cultural, ideológico e internacional es demasiado diferente para extrapolar aquella experiencia a las sociedades contemporáneas.

Tampoco este estudio se ocupa de las pocas sociedades que todavía, o hasta recientemente, estaban sujetas al dominio tradicional de reyes, sultanes o jeques, lo que en términos weberianos serían sistemas feudales o patrimoniales. Por mor de la claridad, es también prudente descartar los casos de transferencia de instituciones democráticas a las antiguas colonias y los intentos de consolidarlas, especialmente en el caso de los estados africanos.

El centro de atención de este artículo son los regímenes no democráticos y no tradicionales y las características políticas e institucionales relacionadas con su desaparición, la probabilidad de las transiciones a la democracia y la consolidación de regímenes competitivos. Es importante distinguir desde el principio entre aquellas sociedades que ya han disfrutado durante un período significativo de un gobierno democrático que fue desplazado por uno no democrático, tal como Alemania, Austria, Italia, España, Checoslovaquia y algunos países de América Latina, y aquellas sociedades en las cuales los regímenes no democráticos sucedieron a gobiernos coloniales o tradicionales sin haber sido precedidos por una democracia. El primer caso implica un proceso de redemocratización, del cual la restauración del régimen democrático previo sería un caso particular ${ }^{4}$. En el segundo caso, cuando la democracia se crea por primera vez, no habrá experiencia del funcionamiento de instituciones democráticas ni una memoria colectiva de las dificultades anteriores de esas instituciones que condujeron a su crisis y quiebra. En gran medida, este análisis se centra en el primer caso, la redemocratización, porque las transiciones con éxito desde gobiernos autoritarios a la democracia en el último medio siglo, dejando de lado a las antiguas colonias, han sido casos de redemocratización.

4 Robert A. KanN, The Problem of Restoration: A Study of Comparative Political History (Berkeley/Los Angeles: University of California, 1968). Kann presenta interesantes ideas sobre el problema. 
Es esencial hacer hincapié en que la crisis y quiebra de los regímenes no democráticos es un proceso que debe mantenerse analíticamente separado del de las transiciones a la democracia política. El colapso de un régimen autoritario puede o no puede crear las condiciones para el triunfo de la democracia política. No es infrecuente que la crisis de un gobierno o régimen autoritario lleve a su sustitución por otro régimen similar, y muchos países han experimentado sucesivos golpes de estado, a veces de orientación ideológica diferente y, en otros casos, el colapso de este tipo de régimen ha llevado a alternativas autoritarias revolucionarias. La inestabilidad del régimen no democrático, por tanto, no conlleva necesariamente el establecimiento de la democracia, a menos que intervengan otros factores.

\section{TOTALITARISMO FRENTE A AUTORITARISMO}

Los científicos sociales han formulado distinciones importantẹs entre regímenes totalitarios y autoritarios, a las que se podría añadir la de los regímenes "sultanísticos" 5 . Las limitaciones de espacio no permiten siquiera intentar definir los tipos ideales que parecen relevantes a los procesos de cambio de régimen, la probabilidad de crisis y quiebras, la forma que toma la transición y el resultado de estos procesos. Si se usa una definición estricta del totalitarismo, se aplicaría a los gobiernos de Hitler, de Stalin y de otros regímenes comunistas, pero no a todos ellos, y probablemente ni siquiera a la Italia de Mussolini. Tales regímenes no fueron derrocados internamente y no condujeron directamente a una transición a la democracia. Como muestra, sin embargo, la historia de la Unión Soviética, estos regímenes han evolucionado a lo largo del tiempo hacia un tipo de gobierno que podría llamarse autoritarismo postotalitario.

No hay acuerdo sobre cuándo y cómo tuvieron lugar estos procesos en la Unión Soviética y en diferentes países comunistas, pero parecen un antecedente importante de los procesos de transición actuales. En algunos estados comunistas, como Polonia, el pluralismo social precomunista se impuso pronto y el régimen autoritario comunista otorgó bastante pronto un papel político independiente a la Iglesia y facilitó la aparición de Solidaridad. Hasta el advenimiento de los importantes cambios que tuvieron lugar en la Unión Soviética con Mikhail Gorbachev, la débil legitimidad del poder comunista en la Europa oriental se reflejó en crisis ideológicas, en tentativas de liberalización, incluyendo la Primavera de Praga, en reformas económicas en Hungría, pero no en êl proceso de crisis y transición del régimen

- Para una tipología de los sistemas políticos no democráticos y mi propia conceptualización, véase Juan LINZ, "Totalitarian and Authoritarian Regimes", en Nelson Posby y Fred Greenstein (eds.), Handbook of Political Science, vol. 111 (Reading, Mass.: Adison Wesley Pres, 1975), pp. $175-482$ 
que finalmente conduciría a la democracia. El incremento del costo de la represión sin la ayuda soviética y el sentimiento creciente por parte de la oposición y el ciudadano medio de que el cambio era posible, forzaron a los gobernantes a iniciar o a aceptar el cambio político. En el caso de Hungría, éste ha tomado una forma no muy distinta de la reforma pactada-ruptura pactada en España, mientras que en Alemania Oriental y en Checoslovaquia las presiones de la oposición y la protesta popular han llevado a alguna forma de poder compartido, incluso antes de las elecciones libres. Sólo en Rumanía, donde los rasgos totalitarios del régimen se combinaban con las características sultanísticas del gobierno de Nicolae Ceauçescu (que algunos comparan con el gobierno de los Somoza en Nicaragua), fue imposible cualquier reforma o transición negociada. Esto condujo a una explosión revolucionaria popular y, a la postre, a la muerte de Ceauçescu. Todo estudio comparativo de estas transiciones no debería olvidar, sin embargo, el legado del totalitarismo, especialmente importante en los dos países comunistas de religión griego-ortodoxa, Bulgaria y Rumanía, ni sus ineficaces economías socialistas.

\section{REGIMENES SULTANISTICOS}

Entre los regímenes no democráticos, algunos están basados en el poder personal con una lealtad al gobernante que no se deriva de la tradición, la ideología, la misión personal o las cualidades carismáticas, sino de una mezcla de miedo y de recompensas a los colaboradores ${ }^{6}$. El gobernante ejerce el poder sin restricciones, a su propia discreción y, sobre todo, sin verse limitado por normas o compromisos con alguna ideología o sistema de valores. Las normas y pautas de una administración burocrática son constantemente subvertidas por las decisiones personales y arbitrarias del gobernante, que no se siente obligado a justificarlas en términos ideológicos.

El personal de tales gobernantes no está constituido por una organización con pautas de ascenso formalizadas, reclutado con criterios más o menos universales, sino en su mayoría por individuos elegidos directamente por el gobernante. A menudo son gentes que por sí mismas no gozan de prestigio o de estima en la sociedad y cuyo poder se deriva exclusivamente del gobernante. Entre ellos a menudo hay miembros de la familia del gobernante, amigos, compinches, socios de negocios e individuos directamente implicados en el uso de la violencia para sostener el régimen.

En caso extremo, el uso del poder personalista y particularista para los fines esencialmente privados del gobernante y sus colaboradores convierte

- El término "sultanístico" está tomado del uso por Max Weber en Guenther RoTH y Claus WiTTICH, Economy and Society, vol. I (Nueva York: Bedminster, 1968), pp. 231-256. 
al país en una inmensa finca. El apoyo no se basa en una coincidencia de intereses entre los grupos sociales privados preexistentes y el gobernante, sino en intereses creados, en recompensas ofrecidas a la lealtad y en el miedo a la venganza. Aunque estos gobernantes no exigen generalmente a la población un apoyo activo, todo el mundo se siente amenazado por su ejercicio arbitrario del poder, impera un miedo difuso y los opositores, o presuntos opositores, son castigados arbitraria y duramente, creándose una atmósfera de terror.

El modo de caer de estos gobernantes, la motivación y la identidad de sus oponentes y las consecuencias a largo plazo de su sustitución probablemente diferirán de las de los regímenes burocráticos autoritarios más establecidos, impersonales y predecibles. En estos regímenes, el gobernante no puede confiar en una amplia base de apoyo procedente de organizaciones tales como un partido único, un ejército profesional disciplinado, intereses organizados o una comunidad religiosa, porque este tipo de gobierno ha destruido y corrompido estas instituciones sociales.

El vacío creado por el gobierno sultanístico hace difícil una oposición organizada basada en estructuras sociales preexistentes y asegura la continuación de estos sistemas de régimen hasta que una rebelión popular o una conspiración elimina físicamente al gobernante y a sus seguidores. El gobierno sultanístico deja un vacío en la sociedad que hace extremadamente difícil el establecimiento y la consolidación de democracias. Su derrocamiento es más probable que lleve a otro régimen no democrático, a veces de características similares al derrocado, o a un régimen revolucionario que intenta crear ex novo fuerzas sociales organizadas, asumiendo el poder sin permitir el desarrollo de fuerzas sociales y políticas competidoras y la relativamente libre competencia de la política democrática. La quiebra y los acontecimientos que la siguieron en los casos de Fulgencio Batista en Cuba, Anastasio Somoza en Nicaragua, Jean-Claude Duvalier en Haití, Mohamed Reza Pahlavi en Irán y Nicolae Ceauçescu en Rumanía, son ejemplos?

\section{ESTABILIDAD E INESTABILIDAD DE LOS REGIMENES AUTORITARIOS}

Al tratar de entender los orígenes de la crisis y derrumbamiento final de los regímenes autoritarios, es útil explorar en qué medida esos orígenes son únicos o son comunes al colapso de otros tipos de regímenes, incluidas las democracias. Algunos serán comunes a tipos de regímenes bastante diferentes, mientras que otros serán específicos del gobierno autoritario o de tipos particulares de régimen autoritario. La legitimidad y efectividad ina-

7 Farideh Farhl, «State Disintegration and Urban-based Revolutionary Crisis: A Comparative Analysis of Iran and Nicaragua", Comparative Political Studies, 21, pp. 231-256. 
decuadas son factores de crisis y de quiebra de muchos tipos diferentes de sistemas políticos ${ }^{8}$.

La eficacia relativa de los regímenes autoritarios es especialmente importante. Definida como la incapacidad para satisfacer las expectativas de la sociedad, para resolver problemas urgentes, tanto internos como externos, es una fuente básica de crisis. Los regímenes autoritarios tienen en su haber una eficacia parcial que a veces no es despreciable. Sin embargo, no pueden traducir esa eficacia en legitimidad política de la forma en que pueden hacerlo las democracias.

Un reto particularmente difícil al que se enfrentan los regímenes autoritarios es la renovación del liderazgo y, en particular, la sucesión. Este es un problema grave en regímenes muy personalizados, en los cuales los fundadores se consideran a sí mismos indispensables, no están dispuestos a abandonar el poder mientras sigan vivos y sienten temor a nombrar a cualquier heredero en potencia. Sin embargo, esta inestabilidad no debería exagerarse, ya que algunos regímenes autoritarios han encontrado mecanismos institucionales para evitar la personalización del poder, como es evidente en regímenes militares recientes, incluyendo los de Uruguay, Perú y Brasil. Sería un error pensar que todos los regímenes autoritarios son vulnerables a las crisis sucesorias.

La importancia de lo que Max Weber consideró la legitimidad en la estabilidad de los regímenes ha sido objeto de considerable discusión ${ }^{9}$. Es imposible ignorar el papel que juega la creencia popular y de las élites en el derecho de los que están en el poder para gobernar en virtud de algún principio indefinido, y la creencia concomitante de aquellos que ejercen el poder en su derecho a hacerlo. Como mínimo, esas creencias implican que una forma concreta de organización política es la mejor posible en una sociedad y un tiempo dados. En muchos regímenes autoritarios esta idea es generada por la convicción, que mantienen sectores significativos de la sociedad, de que un régimen democrático no satisfacería este requerimiento mínimo. La historia demuestra, sin embargo, que esta convicción es probable que se erosione a medida que el tiempo pasa. No hay duda de que la fórmula democrática de legitimación de la autoridad se considera hoy como la más deseable y valiosa en la mayoría de los países. La alternativa democrática parece más legítima que un poder que no tiene que rendir cuentas a la sociedad.

* Sobre legitimidad, eficacia y efectividad en las crisis y fracasos de regímenes, véase LiNZ, La quiebra de las democracias, op. cit. Véanse, también, "Legitimacy of Democracy and the Socioeconomic System", en Mattei Dogan (ed.), Comparing Pluralist Democracies (Boulder, Colo.: Westview, 1988), pp. 65-113; y "Il rapporto tra legitimazione ed efficacia di governo", Mondo Operaio, 3, 1989, pp. 111-116. Para un argumento contrario al uso del concepto de legitimidad, véase Adam PrZEWORSKI, "Some Problems in the Study of the Transition to Democracy", en O'Donell, Schmitter y Whitehead (eds.), Transitions from Authoritarianism, vol. III, pp. 47-84.

9 Véase Linz, La quiebra de las democracias, op. cir. 
La ausencia o la gran debilidad de los principios de legitimación de los regímenes autoritarios contemporáneos tiene muchas fuentes. Hoy no hay ningún país capitalista occidental con una organización política autoritaria y una ideología que cuente como ejemplo legítimo a seguir para otros regímenes autoritarios. La derrota del fascismo como movimiento ideológico de alcance mundial en la Segunda Guerra Mundial y el abandono por la Iglesia católica de la interpretación conservadora del corporatismo, ha dejado a los regímenes autoritarios de todo el mundo sin un sistema ideológico articulado de legitimación atractivo para aquellos sectores de la población cuya política no está basada en intereses, sino en concepciones ideológicas sobre el mejor orden político. Mientras que en los años treinta un cierto número de intelectuales y figuras literarias respetables e incluso destacadas se sintieron atraídas pasajeramente por el fascismo, ninguno de los regímenes autoritarios contemporáneos ha logrado semejante atractivo ${ }^{10}$. Quizá la única excepción ha sido el experimento yugoslavo de autogestión como alternativa a la democracia política. Enfrentados a una crisis y con alternativas democráticas viables en el horizonte, los regímenes autoritarios se han visto seriamente limitados por su falta de legitimidad, y por consiguiente capacidad, para activar compromisos en apoyo del régimen.

Para entender la estabilidad o inestabilidad de los regímenes autoritarios es necesario prestar atención a las circunstancias de su nacimiento, a los cambios económicos y sociales que han tenido lugar bajo ellos, a los cambios en el clima político e ideológico acaecidos entre el momento de su instauración y etapas posteriores y a los cambios en la composición del liderazgo en el curso de su existencia, en vez de percibirlos como sociedades y regímenes inmutables. En este contexto, la duración del régimen se convierte en un factor importante y, quizá en contraste con las democracias, en un factor explicativo de su dispensabilidad y vulnerabilidad. Este tipo de régimen encuentra mucho más difícil incorporar y asimilar los cambios sucedidos en sus entornos sociales, políticos e ideológicos que las democracias, donde la capacidad de actuación de los partidos gobernantes o su sustitución por partidos alternativos facilita la respuesta a tales cambios.

Los gobernantes autoritarios están a menudo obligados a poner en marcha una cierta liberalización con la esperanza de reducir la oposición o incluso cooptarla. Sin embargo, es improbable que tal liberalización satisfaga las expectativas. El proceso de liberalización, a su vez, reduce los incentivos para la participación en las instituciones del régimen y aumenta el espacio para poner a prueba los límites de libertad y de poder, produciendo a menudo un retroceso en el proceso en términos de represión que decepciona las expectativas y aumenta las frustraciones. De este modo, la liberalización puede contribuir al crecimiento de la oposición, en vez de impedirla o neutralizarla. Por otra parte, la vuelta a la opresión se hace sin el limi-

10) Alistair Hamilton, The Appeal of Fascism (Nueva York: Avon, 1971). 
tado apoyo popular que una vez pudo haber tenido y, sin legitimidad, cada vez es más costosa.

El testimonio de las recientes décadas sugiere que el aumento de liberalización de ningún modo asegura la transición a la democracia política. Bajo ciertas circunstancias, puede contribuir a este proceso. También puede llevar a una crisis que traiga consigo el aumento de represión y, quizá en último término, a un derrocamiento violento que hará la democratización aún más difícil. La liberalización no supone un proceso esencial para la transición a la democracia: una transferencia de poder (Macbtübergabe), la abdicación del poder o la toma del poder (Machtergreifung) por algún grupo dispuesto a abrir las puertas a un proceso político democrático, o listo para entregar el poder a aquellos que lo harían ${ }^{11}$.

\section{DIEZ VIAS HACIA LA DEMOCRACIA}

Alfred Stepan ha enumerado diez vías alternativas desde regímenes no democráticos a la democracia política ${ }^{12}$. Como todas las tipologías de la ciencia social, su lista es meramente una simplificación analítica de una realidad más compleja que a menudo engloba una mezcla de vías, algunas ensayadas simultáneamente y otras ensayadas secuencialmente.

Los primeros tres caminos son de relevancia limitada en el presente contexto histórico, pero fueron decisivos para la redemocratización de unas democracias que hoy se consideran entre las más estables, incluyendo las de la República Federal de Alemania y Japón. El primero de los tipos, restauración interna después de una ocupación extranjera, es el menos problemático, porque las democracias restauradas no habían experimentado crisis internas y en un caso, Dinamarca, había continuado operando aun bajo la ocupación nazi. La legitimidad sin interrupción de un gobierno en el exilio se mantuvo indiscutida internamente, excepto por minorías marginales y por la autoridad militar extranjera ocupante.

La segunda vía es la reformulación democrática interna después de la liberación externa. Bajo circunstancias bastante diferentes y, por tanto, con resultados bastante diferentes, éste fue el camino seguido en Francia y Grecia. En algunos aspectos, la Italia de después de 1943 encaja en este tipo.

La tercera vía, más interesante, es la caracterizada como instalación externamente dirigida. El caso más puro es el de Alemania, donde la derro-

11 Rainer M. LEPsiUs, "Machtübernahme und Machtübergabe: Zur Strategie des Regimewechsels", en Hans Albert et al (eds.), Sozialtbeorie und Soziales Praxis: Homage to Eduard Baumgarten, Mannheimer, Sozialwissenschaftliche Studien, vol. 3 (Meisenheim: Anton Hain, 1971), pp. 158- 173.

12 Alfred STEPAN, "Paths toward Redemocratization: Theoretical and Comparative Considerations", en O'Donell, Schmitter y Whitehead (eds.), Transitions from Authoritarian Rule, part. III, pp. 64-84. 
ta total del estado alemán dio a los aliados el control total del desarrollo político. Así, los aliados occidentales crearon una democracia política eficaz y la Unión Soviética creó un falso sistema multipartidista paralelo al occidental pero en el cual estaba asegurada la hegemonía indiscutible del Partido Comunista. Es útil notar que un proceso de democratización externamente controlado no fue incompatible con la creación de instituciones democráticas estables, no contribuyó a su deslegitimación y pudo haber influido en el desarrollo social y político de modo que contribuyó a la futura estabilidad de la República Federal de Alemania.

Estas tres primeras vías en la lista de alternativas de Stepan forman un grupo en virtud de su conexión con la guerra internacional y la intervención externa. Un segundo grupo se deriva de la experiencia de aquellos estados donde los autoritarios inician y controlan el proceso de democratización. El tercer grupo se refiere a aquellos donde las fuerzas de la oposición juegan el papel principal.

Stepan describe tres tipos de transición en los que los poderes autoritarios dan el paso hacia la democracia. Distingue entre transformación dirigida desde dentro del régimen autoritario, transición iniciada por los militares como gobierno y retirada del poder de los militares como institución. Los ejemplos que estudia son los de las recientes transiciones a la democracia en el sur de Europa y en Iberoamérica. Ciertamente, estas tres vías son las más relevantes hoy para la transición a la democracia en un gran número de regímenes autoritarios.

Los cuatro tipos de transición restantes están determinados por los diferentes papeles de la oposición. En dos de estos tipos, las fuerzas de la oposición juegan el papel principal, bien cuando la sociedad como un todo elimina al régimen autoritario o bien mediante un pacto entre partidos políticos de la oposición con o sin elementos "consociacionales" ${ }^{13}$. En los

13 El elemento "consociacional" es el tipo de control de conflictos descrito por Lijphart y por muchos otros que han contribuido a la teoría de la democracia consociacional. Para la discusión de los casos de Colombia y Venezuela, véase Kenneth McRae (ed.), Consociational Democracy, Political Accommodation in Segmented Societies (Toronto: McClelland and Steward, 1974). Véanse Alexander WILDE, "Conversations among Gentlemen: Oligarchic Democracy in Colombia", en Linz y Stepan (eds.), The Breakdown of Democratic Regimes, vol. II, pp. 28-81; Daniel J. Levine, "Venezuela since 1958: The Consolidation of Democratic Politics", ibid., pp. 82-109; Jonathan HARTIYN, The Politics of Coalition Rule in Colombia (Cambridge: Cambridge University Press, 1988). Tanto en Colombia como en Venezuela, los pactos entre partidos y líderes ayudaron a erosionar las bases del régimen autoritario, privándolo de su argumento principal de que en su ausencia se produciría un conflicto sangriento. El hecho de que partidos y líderes, instituciones e intereses, cuyos encarnizados conflictos habían contribuido al derrocamiento de la democracia, pudiesen llegar a acuerdos en la oposición al autoritarismo y en un proceso de redemocratización y consolidación de las democracias fue decisivo para el desalojo de los gobernantes autoritarios. Los mecanismos consociacionales han sido centrales para el proceso de consolidación de la democracia austríaca, y en España durante el período de consenso después de las primeras elecciones de 1977 hasta 1979 y el proceso de elaboración de la Constitución tiene mucho en común con prácticas consociacionales, como han señalado Carlos Hunecus y Richard Gunther. 
dos tipos restantes están implicadas la revuelta violenta o la guerra revolucionaria.

Stepan hace hincapié correctamente en que las vías emprendidas son resultado de la constelación de fuerzas sociales y políticas de las diferentes sociedades, la naturaleza del régimen autoritario y, en cierta medida, del contexto internacional en el que tiene lugar la transición. Señala que seguir una u otra vía conduce a diferentes tipos de democracia, de procesos de cambio socioeconómico y de probabilidades de estabilidad de los regímenes resultantes.

Robert Fishman, en su ensayo sobre las transiciones en el sur de Euro$\mathrm{pa}$, ha refinado el análisis de Stepan al distinguir las transiciones dirigidas por el régimen con la pasividad y aun la hostilidad de instituciones del estado, como las fuerzas armadas, de aquellas dirigidas por las estructuras del estado, tales como fuerzas armadas contrarias al régimen, y, finalmente, de aquellas donde el estado se desintegra y un sector de las fuerzas armadas derroca al régimen. Un ejemplo del primer caso sería España, donde una parte de la clase política del régimen de Franco tomó la iniciativa de la transición. El segundo caso sería el de Grecia, donde las fuerzas armadas que apoyaban el retorno de Konstantinos Karamanlis contra los coroneles acabaron con su gobierno. El tercero sería el movimiento de los capitanes que derrocó a Marcelo Caetano en Portugal, trayendo consigo una reestructuración profunda del estado y cambios revolucionarios.

Nuestro análisis se va a centrar en los tres tipos de transición iniciadas desde los regímenes autoritarios, concretamente en el de las transiciones dirigidas por el régimen. Como Stepan la describe, esta vía subraya el papel del liderazgo autoritario en la iniciación del proceso. Para poder triunfar requiere también la cooperación de la oposición democrática, como se demostró en la transición de España.

Una de las cuestiones más interesantes sobre el proceso de transición es decidir quién gobernará en el interín entre la decisión de liquidar el régimen autoritario y el momento en que pueda formarse un gobierno basado en unas elecciones democráticas libres. Esta cuestión está lejos de ser académica e implica opciones básicas de importancia considerable para el mismo proceso de transición, la naturaleza del sistema democrático emergente y su estabilidad futura ${ }^{14}$.

Hay dos alternativas. La oposición democrática argumentará que el régimen autoritario carece de legitimidad para continuar gobernando y pedirá la instalación de un gobierno provisional completamente «democrático". El contraargumento es que los partidos recién autodefinidos también carecen de legitimidad democrática hasta que el electorado haya decidido su apoyo. La cuestión que se debate no es la de la legitimidad democrática;

14 Robert M. FiSHMAN, "Rethinking State and Regime: Southern Europe's Transition to Democracy", World Politics, 42, 3, 1990, pp. 422-440. 
más bien es la de quién controlará muchos recursos políticos en el período de transición y si la oposición democrática tendrá oportunidad de emprender transformaciones importantes en la sociedad antes de las elecciones.

Ninguna opción garantiza en todos los casos una transición con éxito a la democracia, y el conflicto manifiesto sobre esta cuestión bien podría entorpecer el proceso de transición. Depende tanto del nivel de confianza en la honradez de los que participan en la institucionalización de la democracia como del equilibrio relativo de poder entre los adversarios. La continuidad del poder en los sucesores legales del régimen autoritario es probable que neutralice los temores de los defensores del status quo y, en particular, de la institución militar: Tal continuidad también puede contribuir a moderar las demandas y actividades de los que desean un cambio social radical y, de ese modo, reducir los temores en el período crucial de transición. Esta solución, sin embargo, es posible sólo cuando el aparato del estado del régimen anterior no se ha desintegrado, cuando no se hace directamente responsables de los peores rasgos del antiguo régimen a los que van a asumir el poder $y$, por tanto, cuando éstos tienen capacidad para negociar con la oposición algunas reglas fundamentales para la transición y dar alguna prueba de su buena fe.

La alternativa de la transferencia de poder a la oposición antes de las elecciones resulta de la situación opuesta: la desintegración del aparato del estado, especialmente la división dentro de las fuerzas armadas, la creación de un vacío de poder que permita la movilización rápida de las masas que lleven a cabo con éxito acciones espontáneas, y la debilidad o ausencia de un liderazgo que surja del viejo régimen tan presto a mantener el poder como a hacer posible una elección libre. Si bien un gobierno de demócratas comprometidos, el poder de un gobierno provisional está más cerca de la dictadura en el sentido clásico del término que de un gobierno de gestión que prepara elecciones. De hecho, algunos elementos de tal gobierno provisional podrían estar tentados a ampliar su poder más allá de unos ciertos límites y a establecer condiciones para la participación en el proceso electoral de los partidos políticos y directivas para el desarrollo futuro de la constitución.

Uno de los grandes desafíos del período entre el gobierno autoritario y el primer gobierno basado en elecciones libres es el establecimiento de las reglas básicas del futuro proceso político, tanto de las características de las instituciones representativas que se van a establecer como la ley electoral.

\section{REFORMA O RUPTURA: UN FALSO DILEMA}

Las dos palabras que se convirtieron en parte del lenguaje político durante la transición a la democracia en España han sido y son presentadas como dos vías alternativas a la democracia. Ambas tienen sus apologistas y 
sus críticos y mucho del debate político gira en torno a ellas en países donde ha fracasado la estabilización de un régimen autoritario o tal régimen se aproxima a un estado de crisis.

Las transiciones desde el autoritarismo a la democracia tienden a iniciarse cuando los líderes del régimen autoritario empiezan a considerar la posibilidad de una reforma que conduzca a alguna forma de democracia política. La oposición al régimen autoritario favorece en principio una ruptura, un corte con las disposiciones institucionales existentes, un cambio no controlado por los que, en una u otra medida, tenían algo que ver con el régimen previo e incluso sin su participación. Llevados por la indignación moral, les gustaría ver a aquellos que han tenido parte en el poder privados, si no formalmente de derechos políticos y acceso a los cargos públicos, sí de toda oportunidad de participar en el proceso. Estas posiciones, en principio, son irreconciliables y, a menos que los partidarios de la ruptura logren el apoyo de un sector importante de las fuerzas armadas o sean capaces de movilizar al pueblo para el derrocamiento violento del régimen, parece improbable que los que están en el poder accedan libremente a abdicar y a dejarles espacio. La estrategia de una ruptura clara es viable sólo en una situación revolucionaria o potencialmente revolucionaria.

Una transformación guiada por los que están en el poder y sin participación de la oposición sería posible bajo ciertas circunstancias, como en el caso de la transición a la democracia en Turquía en 1947. También hay casos de ruptura exitosa, como lo demuestra el ejemplo de Portugal en 1974. Sin embargo, esto no debería oscurecer el hecho de que en la mayoría de los regímenes autoritarios ninguna de ambas estrategias está realmente disponible ni para los que están en el poder ni para los que están en la oposición.

Paradójicamente, la transición a veces es posible por la formulación simultánea de ambas posiciones como posturas, con propósitos de negociación más bien que como posiciones finales. De hecho, si ambas posiciones tienen recursos de poder comparables aunque de naturaleza diferente, o si ambas son relativamente débiles debido a la apatía de grandes sectores de la población, la transición sólo será posible mediante un complejo proceso que implica a la vez reforma y ruptura ${ }^{15}$.

No hay espacio para describir los múltiples movimientos de los diversos jugadores en el complejo juego político implicado en las transiciones, las dudas de los líderes de la oposición acerca de si aceptar las ofertas de los reformadores, las consiguientes tensiones entre los tenaces abogados de la ruptura y los que quieren poner a prueba la voluntad de los reformadores, el despliegue de fuerza por parte de los distintos actores con el fin de convencer a los negociadores de que encuentren soluciones a los múltiples y

is Juan J. LinZ, "ll Fattore tempo nei mutamenti di regimi", Teoria Politica, 1, 1986, pp. 3-48. Véanse especialmente pp. 16-23. 
complejos problemas específicos, la elaboración de acuerdos sobre la ley electoral, las condiciones para la campaña y el recuento de votos, etc. ${ }^{16}$. Cada una de estas decisiones puede crear una crisis que parecerá amenazar a todo el proceso. En algunos casos, es el liderazgo de los reformadores del régimen el que toma la iniciativa, en vez de esperar a que los acontecimientos y la dinámica de una situación volátil ejerzan presión sobre ellos ${ }^{17}$. En otros, se dan los pasos necesarios demasiado tarde y de forma indecisa, frustrando así la posibilidad de acuerdo.

Muchas de las propuestas de los reformadores se quedarán cortas respecto a la democratización real, y si el intento fracasa, todo el proceso podría retrasarse o incluso podría abortar a causa de la radicalización de la oposición frustrada y de la airada respuesta de algunos aspirantes a reformadores. Este fue, en parte, el sino de Caetano en Portugal y era una posibilidad si Arias Navarro hubiera continuado como jefe de gobierno en España.

Es útil notar que el compromiso con unas elecciones libres y limpias acelera el proceso de transición y legitima temporalmente al gobierno existente de cara a la oposición moderada, rebaja la movilización para el derrocamiento del gobierno y fuerza a los líderes de la oposición a asumir posiciones responsables, así como a posponer las demandas de unos cambios en la política que ahora pueden esperar conseguir después de las elecciones.

Navegar con éxito en estas peligrosas aguas requiere actores políticos con un grado considerable de racionalidad, con capacidad para no dejarse engañar por las jactancias y las amenazas de los otros. Requiere también que el gobierno mantenga el orden público y el monopolio de la violencia organizada y probablemente que aumenten los contactos y la confianza entre los líderes más importantes y responsables. Sin duda, la situación internacional puede contribuir positiva o negativamente a este complejo proceso, por un lado dando apoyo al mismo y desalentando las esperanzas revolucionarias, y por otro apoyando el mantenimiento del status quo ${ }^{18}$.

16 Sobre la transición española, véanse José Félix Tezanos, Ramón Cotarelo y Andrés de Blas (eds.), La transición democrática española (Madrid: Editorial Sistema, 1989) (además de los ensayos, incluye una bibliografía detallada y una cronología de la transición); Jose María Maravall y Julián Santamaría, "Political Change and the Prospects for Democracy", en O'Donell, Schmitter y Whitehead (eds.), Transitions from Authoritarian Rule, parte I, pp. 71108; Paul PRESTON, The Triumph of Democracy in Spain (Londres: Methuen, 1984).

17 Juan J. LiNZ, "Innovative Leadership in the Transition to Democracy and a New Democracy: The Case of Spain", trabajo presentado en la Conferencia sobre liderazgo innovativo y política internacional, Instituto Leonard Davis para las Relaciones Internacionales, Hebrew University, Jerusalén, 8-10 de junio de 1987.

18 Este desarrollo se afirma claramente en la Primera Tesis presentada al Congreso del Partido Comunista de España (abril 1978): "La ruptura política radical realizada de una sola vez, con la instauración de un gobierno provisional, como preconizaban el Partido Comunista y la Junta Democrática, no fue posible por varios factores, entre los que cabe destacar la orientación reformista tomada por algunas fuerzas de la oposición y las surgidas del mismo régimen franquista, así como por la presión internacional, fundamentalmente europea y 
Caben pocas dudas respecto a que el modelo de negociación y compromiso entre las fuerzas de la reforma y de la ruptura que acabamos de describir no triunfará igualmente en todas las sociedades, aun cuando lo apoyen líderes del ala reformista del gobierno y moderados de la oposición. Aunque el proceso de democratización es fundamentalmente un proceso político, sería absurdo ignorar las condiciones limitadoras y restrictivas que impone la estructura socioeconómica de las diferentes sociedades. Lo que fue posible en España y más lentamente en Brasil, será ciertamente infinitamente más difícil en Bolivia o en Guatemala.

Un aspecto que no puede discutirse aquí en detalle es el papel en este período de los intereses organizados, tales como los sindicatos, grupos financieros, asociaciones patronales y ligas campesinas. No hay que olvidar que el clima de libertad creciente estimulará probablemente la aparición de este tipo de organizaciones, las expresiones de reivindicaciones reprimidas, la correspondiente interrupción del proceso productivo y del funcionamiento normal de los servicios públicos, los miedos de las clases propietarias e incluso los actos de venganza personal. Una de las consecuencias puede ser el descenso de la producción y un incremento de salarios y precios que provoque una espiral inflacionaria.

El análisis de las diferentes vías que van desde el autoritarismo a la democracia, muy en particular la transición mediante transacción (el modelo de reforma pactada-ruptura pactada), tiende a centrar la atención en los acuerdos de la élite, el papel de los líderes del régimen y de la oposición, el búnker, los demócratas y los revolucionarios, e inevitablemente reduce el papel del pueblo.

Nunca debería olvidarse que, en las transiciones, la mujer, el hombre medio, los estudiantes y los trabajadores se manifiestan en las calles, corriendo riesgos al organizar grupos ilegales, distribuyendo propaganda y, en unos pocos casos como Rumanía y Nicaragua, asaltando las sedes del poder. Estas gentes y sus acciones juegan un papel importante y aun decisivo. Esto es cierto aun en aquellas transiciones iniciadas desde el régimen o el estado, que sin la presión desde abajo no tendrían justificación ni apoyo. Sin embargo, un pueblo sin líderes y desorganizado, que llene las calles exigiendo un cambio de régimen, puede ser incapaz de negociar una transferencia del poder o la participación en él, o los procesos para lograr ese fin, y puede ser empujado hacia posiciones intransigentes y, de este modo, sus esfuerzos acabarán, si no en revoluciones, sí en represión. La reciente y

americana, temerosa de la hegemonía de la clase obrera y las fuerzas de izquierda. Estos factores influyeron en que el movimiento de masas, pese a su amplitud e importancia, no alcanzase la fuerza necesaria para determinar una ruptura política radical. Tal situación obligó al PCE a matizar sus tesis rupturistas en la solución de la ruptura pactada. Y, de hecho, el proceso de cambio ha venido transcurriendo como tal ruptura pactada, aunque este pacto sea puramente tácito, tras el desplazamiento por la lucha de masas del gobierno reaccionario e inmovilista de Arias Navarro." Mundo Obrero, semana del 2 al 8 de febrero de 1978. 
trágica experiencia china es un ejemplo. Por tanto, el pluralismo social limitado, la semilibertad o pseudolibertad de muchos regímenes autoritarios o un período prolongado de crisis del régimen, ha hecho posible a veces la aparición de una oposición estructurada del tipo necesario para poder jugar un papel en la transición y, si está comprometida con la democracia, poder llevarla a cabo.

\section{REDEMOCRATIZACION Y TIPOS DE REGIMEN}

A primera vista puede parecer como si la elección entre autoritarismo y democracia política fuera una simple cuestión de acordar que en el futuro el poder deberá ir a los que gocen del apoyo popular expresado en unas elecciones libres y limpias. Sin embargo, las cosas no son tan simples porque las democracias difieren considerablemente en la forma en que el poder se distribuya a través de los procesos electorales. Hay que tener en cuenta que el gobierno democrático es también gobierno constitucional, esto es, gobierno dentro de ciertos ordenamientos institucionales acordados por los participantes como válidos para más de una situación, que no se cambien fácilmente y a diario. La elaboración de la constitución y los debates sobre normas constitucionales alternativas fueron el núcleo de la ciencia política y el debate político en el siglo XIX e incluso en las primeras décadas del $\mathrm{xx}$, pero este interés en gran medida se ha perdido con la revolución conductista y el creciente énfasis en los factores socioeconómicos y las políticas alternativas. Las actuales tipologías de democracia prestan poca atención a los factores institucionales y las normas constitucionales se dejan para el debate entre los profesores de las facultades de derecho y para los abogados. En la práctica, los políticos tampoco pueden ignorar esas cuestiones.

¿Supone alguna diferencia para el éxito de la transición a la democracia que el nuevo régimen sea presidencial o parlamentario, unitario o federal, unicameral o bicameral? La literatura of rece pocas respuestas a estas preguntas, aunque debería estar en el centro mismo de la atención de los estudiosos de las transiciones. La elección entre parlamentarismo, presidencialismo y un régimen semipresidencial tiene implicaciones importantes para la transición a la democracia y para su consolisación ${ }^{19}$. Aunque no hay nin-

19 Véase Juan J. Linz, "Democracy: Presidential or Parlamentary. Does it Make a Difference?", presentado en un seminario del Woodrow Wilson International Center for Scholars en 1984, del cual fue publicado un pequeño extracto: Juan J. LiNZ, "Perils of Presidentialism", Jounal of Democracy, 1: 1 (invierno 1990), pp. 51-69. La versión completa está en Oscar Godoy (ed.), Hacia una democracia modema. La opción parlamentaria (Santiago, Chile: Ediciones Universidad Católica de Chile, 1990). En una reunión en la Universidad de Georgetown, organizada por Arturo Valenzuela y el autor, académicos de diversos países presentaron trabajos sobre el problema que serán publicados en un futuro próximo. Véase, tam. bién, Scott MAINWARING, "Presidentialism in Latin America", Latin American Research Revieu, vol. 25, 1, 1990, pp. 157-179. 
gún estudio exhaustivo de la evidencia empírica, la experiencia histórica sugiere que una democracia presidencial, como la de los Estados Unidos y la de muchas constituciones latinoamericanas, crea dificultades específicas en el proceso de redemocratización. Un sistema presidencial incrementa la amenaza que la transición a la democracia, con sus incertidumbres sobre quién y de qué forma alguien debe gobernar, representa para aquellos que podrían ser derrotados. Es más probable que el presidencialismo cree una situación de suma cero que el parlamentarismo, al dar considerable poder a un líder individual durante un período fijo de tiempo. Un sistema presidencial limita las expectativas de influir en el proceso político de los que podrían estar en minoría. El presidencialismo incluso limita la influencia después de las elecciones de los diferentes partidos que forman una coalición para elegir a un candidato concreto, a menos que vuelvan a tácticas opositoras que pueden contribuir a crear una situación de crisis. Es probable que el presidencialismo alimente un proceso de polarización en una sociedad dividida y, a menudo, requiere la coalición de los moderados con los que están en posiciones más extremas.

El parlamentarismo puede evitar algunas de las rigideces del presidencialismo. Las primeras elecciones libres no dan necesariamente a un solo líder una posición dominante durante un período de cuatro años (o más), aunque en la práctica el deseo de estabilidad gubernamental llevará a disposiciones como la del voto constructivo de desconfianza alemán y el tipo de gobierno de canciller. Combinado con la representación proporcional, los distintos partidos pueden mantener su identidad, llegar a acuerdos sobre algunos problemas y no sobre otros. Las posiciones más extremas se pueden aislar o incorporar al proceso de reforma ad hoc. Los moderados más próximos a la oposición y al régimen autoritario anterior pueden cooperar en la fase de institucionalización del proceso de instauración, pero también pueden divergir en políticas concretas.

Ciertamente, el parlamentarismo también puede contribuir a la inestabilidad del gobierno democrático, haciendo más difícil e ineficaz el acto de gobernar. La cuestión es que, en la fase de instauración, una forma parlamentaria de democracia permite una mayor distribución de los costos y los beneficios del cambio y de las consecuencias amenazadoras de la toma de algunas decisiones.

Podría argumentarse que en una fase tan crítica de transición un presidente destacado podría jugar un papel similar al de los líderes políticos en el parlamento y tomar decisiones mediante compleja negociación. Esto supone, sin embargo, la disponibilidad de un candidato de esas características para ocupar la presidencia. 


\section{MILITARES Y DEMOCRATIZACION}

Los científicos sociales especulan sobre si hay una conexión directa entre diferentes tipos de regímenes autoritarios y las vías a la democracia que emprenden. Tal especulación es breve porque la respuesta parece ser que no la hay; la política es una empresa mucho más compleja. Sin embargo, una característica del proceso que parece conformar los resultados significativamente es la importancia relativa de las fuerzas burocrático-militares en los regímenes autoritarios salientes ${ }^{20}$.

Existe la posibilidad de que la democratización la inicien líderes individuales del gobierno militar, en vez de los militares como institución corporativa. Este ha sido el caso de Brasil, donde la apertura iniciada por el presidente Geisel y su principal aliado, el general Golbery, condujo a un proceso de liberalización, a una autonomía progresivamente mayor de la sociedad civil, a elecciones cada vez más libres para ciertos cargos y, por último, a causa de la creciente presión popular, a la elección por parte de un colegio electoral de un presidente civil. Este lento proceso no fue visto con simpatía por importantes sectores de los militares.

Este modelo contrasta con lo casos en que los militares como institución desean quitarse de encima el poder con el fin de defender la autonomía de la institución y su capacidad para la defensa nacional sin ser culpados por su papel de gobernantes, como el ejército griego después de la crisis de Chipre o el ejército peruano.

Una decisión así tomada es algo diferente de la aquiescencia o tolerancia por parte de las fuerzas armadas del proceso de democratización tal y como lo dirige un gobierno civil. Aunque los científicos sociales son propensos a olvidarlo, hay una diferencia fundamental entre poder formal e informal, entre influencia y autoridad formal.

Incluso en un régimen autoritario, los civiles tienen lazos más estrechos con la sociedad civil, viven en un mundo menos aislado y restringido que los oficiales y se dedican a actividades profesionales que los ponen en contacto con un sector más representativo de la población. Durante sus carreras, muchos civiles establecen lazos personales con los que serán líderes de la oposición, algo mucho menos probable en el caso de los oficiales del ejército. Esos múltiples lazos y asociaciones pueden ser muy importantes en el proceso de negociación de la transición.

Aparte de la posición que los militares ocupen en las estructuras forma-

20 Alfred StePAN, Retbinking Military Politics: Brazil and the Southern Cone (Princeton, N. J.: Princeton University Press, 1988); Felipe AGÜERO, "The Military in the Processes of Political Democratization in South American and Southern Europe: Outcomes and Initial Conditions", trabajo presentado en el $15 .^{\circ}$ Congreso Internacional de la Asociación de Estudios Latino Americanos, 1989; Alain RovQuie, "Demilitarization and the Institutionaliza. tion of Military-Dominated Politics in Latin America", en O'Donell, Schmitter y Whitehead (eds.), Transitions from Autboritbarian Rule, parte III, pp. 108-136. 
les de poder en un régimen autoritario, su postura ante la democratización será importante. A diferencia de cualquier otro grupo de la sociedad, los militares pueden imponer su voluntad poniendo tanques en las calles. Algunos casos de redemocratización fueron iniciados por un sector de las fuerzas armadas, como en Portugal, o con la cooperación de los militares, como en Venezuela. Por otra parte, los militares pueden vetar el proceso de reforma por la fuerza. Es útil recordar el dictum de Maquiavelo de que no es razonable que los que están armados deban obedecer a los que están desarmados, y en la mayoría de las sociedades sólo las fuerzas armadas están eficazmente armadas. Sería un gran error asumir que la institución militar es necesariamente hostil a las políticas democráticas y de partido, aunque por su mentalidad esté menos dispuesta, o sea menos comprensiva con algunas de las inconsistencias de las políticas de los partidos y de la falta de unidad de propósito y de disciplina que tan a menudo se asocia con la democracia. No hay que olvidar la otra cara de la historia: la posición antimilitarista, latente o manifiesta, de muchos políticos demócratas, frecuentemente tan mal informados e insensibles ante los problemas del mundo militar como lo es la falta de simpatía de algunos oficiales hacia los civiles. En una democracia estable, y en cierta medida en un régimen autoritario estable, estas tensiones latentes y las diferencias de mentalidad no son políticamente relevantes, pero en un período de cambio político pueden ser centrales.

La implicación activa de los militares en la democratización de ciertas sociedades plantea dilemas no diferentes de los planteados por las sociedades multinacionales y multiétnicas, suscitando cuestiones acerca de si el modelo de política democrática abstracto, normativo y puro es realizable de forma inmediata en todas las sociedades. Este dilema sugiere que las instituciones democráticas más imperfectas, limitadas y parcialmente distorsionadas podrían ser a veces viables cuando, a corto plazo, es inviable realizar la soberanía completa del pueblo y de sus representantes elegidos. Esto plantea la difícil y delicada cuestión de cuánta desviación del modelo ideal es posible sin renunciar al principio fundamental y a la esperanza de una mayor realización del ideal.

Este problema se complica por el hecho de que los militares es probable que tengan también fuertes convicciones, derivadas de consideraciones geopolíticas, sobre la posición internacional del país, convicciones que limitan las opciones de política exterior e, indirectamente, algunas de las políticas económicas y sociales alternativas de cualquier tipo de régimen que esté en el poder. Aunque los ciudadanos puedan lamentar este hecho, los científicos sociales están obligados a valorar su importancia respecto a los procesos de democratización y su relevancia para una realización más limitada de la democracia política, lo cual plantea la cuestión básica de si la democracia merece que se hagan compromisos. Es prudente recordar que el proceso de democratización de las democracias europeas hoy estables y 
soberanas, se logró mediante compromisos y conflictos constantes con la autoridad real y con los poderes residuales de las segundas cámaras aristocráticas o de notables.

Parece dudoso que en la fase de transición puedan ingeniarse mecanismos formalizados o pactos y disposiciones legales y constitucionales para manejar estos problemas de los militares y la democratización. La experiencia reciente sugiere que sería más deseable alcanzar informalmente entendimientos vinculantes y desarrollar ciertos límites y prácticas aceptables. Sin embargo, esto requiere una cierta honradez y seriedad del liderazgo frente a esos compromisos y una capacidad para defenderlos ante otros. Aquí, como en tantas otras ocasiones, la dificultad radica en el vacío de liderazgo y de densidad organizativa que tan a menudo deja como herencia el régimen autoritario.

El cambio político súbito y rápido en los países comunistas de Europa y en la Unión Soviética ha tomado por sorpresa a los científicos sociales. Obviamente, el totalitarismo había sido desplazado por el autoritarismo en Polonia hace algunos años. Incluso la Unión Soviética hace mucho que no encajaba en el tipo ideal de totalitarismo, aunque no había consenso sobre cuándo ocurrió con precisión o sobre cómo conceptualizar la política soviética. Ciertamente, muchos estados comunistas del Este europeo eran postotalitarios, habiendo experimentado períodos y procesos de liberalización, una decadencia de la ideología y una crisis de las organizaciones de masas. Incluso así, una transición a la democracia política pluralista no parecía estar en las cartas. Es demasiado pronto para analizar los procesos que han llevado al cambio, los diferentes caminos que la democratización ha tomado y, aún menos, los tipos de régimen que actualmente están emergiendo, especialmente en el caso de la Unión Soviética. Hay, sin embargo, similitudes con los procesos que han tenido lugar en otras partes.

Los cambios iniciados por Mikhail Gorbachev — gladnost y perestroikason cambios desde arriba reforzados y acelerados desde abajo y probablemente van más allá de su intención original. La retirada del paraguas protector de la Unión Soviética hizo visible la baja legitimidad de los regímenes de postguerra impuestos en la Europa oriental. La retirada soviética hizo cada vez mayor el coste de la represión una vez que la oposición logró coraje para manifestarse y el coste de la tolerancia, en términos de riesgo de intervención soviética, se hizo menor. Al mismo tiempo, la crisis de eficacia de la economía socialista, incluyendo la de la Unión Soviética, hizo imperativa la búsqueda de nuevas soluciones que incluían el cambio político.

Significativamente, parece no haber un solo modelo de transiciones en los países comunistas, sino respuestas distintas que reflejan la diferente evolución del régimen en años anteriores. En un extremo está Rumanía, donde el régimen de Ceauçescu, entre sultanístico y totalitario, no dejó otro camino que la revuelta popular y condujo a un gobierno provisional 
cuyos planes son inciertos y que podría no desembocar en la democracia. En el otro extremo está Polonia, donde a través de los años se había desarrollado un cierto pluralismo limitado y una oposición bien organizada logró el poder en unas elecciones, aunque tuvo que compartirlo con los comunistas. Este último caso recuerda la diarquía de partidos democráticos y militares en la transición brasileña. Hungría parece seguir más el modelo español, con un régimen que inicia el cambio y retiene el poder hasta después de las elecciones. Las soluciones checa y alemana, con un poder limitado compartido entre el régimen y la oposición, no ha tenido paralelo en las transiciones occidentales en el período antes de las elecciones. Todas las transiciones en los países comunistas son, sin embargo, fundamentalmente diferentes de las de Occidente, debido a la presencia de sus ineficaces economías socialistas de planificación centralizada. Estos países deben realizar reformas económicas y transiciones a alguna forma de economía de mercado al tiempo que acometen la reforma política, o como resultado del cambio político. Hay indicios de que los cambios en el sistema económico presentan mayor dificultad que el cambio político, en parte debido a que todavía no hay un modelo de transición de una economía planificada centralizada autoritaria a una economía de mercado y a alguna forma de capitalismo.

La crisis del socialismo de estado y de las economías planificadas y centralizadas ha llevado al reconocimiento de la necesidad de introducir mecanismos de mercado, incluso con propiedad privada de los medios de producción. Esto es algo que muchos llamarían capitalismo, pero en la práctica continuará siendo una economía mixta con consecuencias no limitadas a los países comunistas. No hay que olvidar que en muchas democracias cerca de la mayoría de la población estaba en principio, aunque no necesariamente en la práctica, a favor de una economía socializada y que los gobiernos democráticos que no socializaron los medios de producción estaban protegiendo o legitimando indirectamente los sistemas económicos capitalistas, a veces más eficazmente de lo que podría hacerlo cualquier gobierno autoritario. El algunos cásos, al hacerlo corrían un riesgo al no realizar la voluntad popular. Ahora, con la mayor legitimidad de la economía de mercado, esta tensión es probable que se reduzca. Indirectamente, la crisis del socialismo completo, no los principios del estado de bienestar ni las economías mixtas, contribuye a la estabilidad y legitimidad de las democracias no deseosas o incapaces de hacer una transición al socialismo.

\section{CONSOLIDACION DEMOCRATICA}

¿Cuándo ha finalizado la transición? ¿Cómo se sabe cuándo la consolidación se ha completado? Generalmente, la transición empieza con un suce- 
so especialmente dramático, aunque el poder de tal suceso se manifieste a menudo como la culminación de una serie de acontecimientos. Frecuentemente, este hecho tiene como resultado el compromiso público y oficial de los gobernantes autoritarios de realizar elecciones libres y devolver el poder al electorado en una fecha fija. Puede tener también como resultado un golpe o una insurrección revolucionaria que obliga a los gobernantes a abandonar el poder y huir o ser asesinados, dejando un nuevo grupo autodesignado con un poder temporal que parece comprometido a realizar elecciones o a transferir el poder al electorado. El ingrediente esencial de una transición es la expectativa, tanto por parte del pueblo como por parte de los que detentan el poder, de que la autoridad política pronto se derivará sólo de la libre decisión del electorado.

¿En qué punto termina este período de transición, estrictamente definido? De nuevo, la decisión de cuándo se ha llegado a ese término es en alguna medida arbitraria, pero no hay duda de que la celebración con éxito de elecciones libres, la convocatoria de un nuevo parlamento de cuya confianza depende el gobierno o la inauguración de un nuevo presidente en le cargo, sería tal momento.

Esta es la definición más estricta del período de transición, pero sería razonable decir que hasta que los representantes electos creen o restauren un marco constitucional básico que defina las funciones de los distintos órganos de gobierno, no puede considerarse que una democracia está plenamente establecida. Desde esta perspectiva, la fase de elaboración de la constitución es aún parte del proceso de transición, porque ésta no puede considerarse terminada hasta que haya un marco legal que defina los procedimientos por los cuales se pueda designar a los que ejercen el poder ejecutivo, así como los poderes respectivos del legislativo, el ejecutivo y, en algunos casos, el judicial para decidir los conflictos institucionales.

El período de redacción de la constitución es parte integrante del período de transición porque el grado de consenso que se logre será un elemento importante para la estabilidad o inestabilidad de la política futura de la sociedad. La aprobación de una constitución que satisfaga sólo a la mayoría y sea totalmente rechazada por la oposición, difícilmente puede considerarse que crea un marco para la política cotidiana y un gobierno estable. En este sentido, la democracia española comenzó sobre una base más sólida con la Constitución de 1978 que la República en 1931 con una constitución fuertemente contestada.

La aparición de un número importante de nuevos regímenes democráticos plantea la cuestión de su grado de consolidación o estabilidad. Hay quienes consideran que la terminación de la transferencia de poder a un gobierno o presidente electos es una prueba insuficiente de consolidación, especialmente en vista de la ardua tarea con la que se enfrentan estos gobiernos. No hay consenso académico acerca de cómo definir la consolidación. Las opiniones varían desde una concepción minimalista a una que 
incluye el desarrollo de todas las instituciones de la nueva democracia: todas las pautas de mediación de intereses, la consolidación de un sistema de partidos, la transferencia efectiva del poder a un partido de la oposición, etcétera. En opinión de este autor, una definición maximalista de consolidación haría casi imposible decir que cualquier régimen democrático está ya completamente consolidado y llevaría a que las crisis futuras se expliquen como resultado del fracaso de la consolidación, en vez de por la incapacidad del régimen para hacerles frente.

Este autor argüiría a favor de una concepción minimalista de un régimen democrático consolidado, esto es, uno en el cual ninguno de los principales actores políticos, partidos o intereses organizados, fuerzas o instituciones, consideren que hay alguna alternativa a los procesos democráticos para obtener el poder, y que ninguna institución o grupo político tiene derecho a vetar la acción de los que gobiernan democráticamente elegidos. Esto no significa que no haya minorías prestas a desafiar y cuestionar la legitimidad de los procesos democráticos por medios no democráticos. Significa que los actores principales no recurren a ellos y que permanecen políticamente aislados. Por decirlo simplemente, la democracia debe ser considerada como el "único casino de la ciudad", para utilizar una expresión del viejo Oeste.

El hecho de que ciertas instituciones, tales como las fuerzas armadas en algunos países latinoamericanos y quizá el partido comunista y la nomenklatura, puedan tratar de ejercer el veto o de compartir el poder independientemente del resultado de las elecciones, puede llevar a considerar a esas democracias como no plenamente consolidadas. Por ejemplo, la democracia chilena, hasta que se reforme la Constitución de 1980 -dados los poderes retenidos por los militares- probablemente no se consideraría completamente consolidada. La respuesta de todas las fuerzas políticas al intento de golpe del 23 de febrero de 1981 en España, que aunó en su condena a los líderes sindicales y de la patronal y desde el Partido Comunista a Alianza Popular, sumada a la capacidad del gobierno español de entonces para procesar a sus líderes, es un ejemplo de consolidación. El hecho de que algunas democracias puedan ser ineficaces a la hora de solucionar graves problemas no debiera confundirse con falta de consolidación, aunque se podría calificarlas como democracias con riesgo de inestabilidad. Indudablemente, algunas democracias podrían no estar totalmente consolidadas y al mismo tiempo verse asediadas por los problemas a los que se enfrentan y, por lo tanto, en peligro de quiebra.

La consolidación democrática se enfrenta a menudo con el grave reto de cómo tratar justamente a los gobernantes no democráticos previos, especialmente en lo que respecta a las violaciones de los derechos civiles. Los pasos que se den para imponer alguna forma de justicia son especialmente importantes cuando aquellos abusos eran injustificables incluso en términos de la legislación del régimen anterior, tales como las desaparicio- 
nes y las torturas ${ }^{21}$. También está la difícil cuestión de depurar de las fuerzas armadas, la burocracia e incluso de actividades privadas como grandes empresas de negocios, a colaboradores del antiguo régimen. Los nuevos regímenes democráticos han seguido políticas bastante distintas en este campo y no está claro si contribuyen a la consolidación o si crean más problemas de los que resuelven.

Algunos argumentan que la democracia no está plenamente consolidada hasta que el poder se ha alternado de un equipo de líderes elegidos a otro, hasta que el partido o los partidos que gobernaron como resultado de las primeras elecciones democráticas han sido sustituidos, sin mayores tensiones o crisis, por la oposición. Esto parece una interpretación innecesariamente estricta, dado que la hegemonía de un partido a menudo es duradera y que tal alternancia es la excepción más bien que la regla en las democracias. Llevado al extremo lógico, este argumento conduciría al absurdo de que la democracia japonesa no se ha consolidado.

Es difícil separar el proceso de creación de instituciones políticas democráticas, la defensa de esas instituciones y su legitimación, de los procesos de cambio económico, social y cultural que resultan de su establecimiento. Cuanto menos se asocien estos cambios fundamentales con la transición del régimen, más fácil será para ciertos sectores de la sociedad soportar las privaciones derivadas del cambio, en el sentido de que las instituciones democráticas no sufrirán posteriormente sus iras o sus intentos de rechazar el sistema político. Por decirlo de forma epigramática, hay cambios dentro de un régimen democrático, pero no cambios por el régimen democrático. Una de las bases de la legitimidad de la democracia es su relativa apertura a cambiar el contenido sustantivo de la política. Por otro lado, las gentes no suelen identificarse con las instituciones y los procesos democráticos en abstracto, por lo que los nuevos regímenes democráticos sólo pueden ganarse la lealtad popular llevando a cabo cambios sociales reales que afecten a sus vidas cotidianas.

Está lejos de ser fácil el decidir cuál de estas alternativas puede contribuir más a la consolidación y, en última instancia, la estabilización de un nuevo régimen democrático. Por un lado, en sociedades con graves problemas sociales y económicos, en las que grandes sectores de la población se han sentido muy desfavorecidos, una democracia que no lleva a cabo relativamente pronto importantes cambios sociales se verá desafiada por el descontento de las masas, produciéndose quizá conflictos violentos que pueden desembocar bien en violencia revolucionaria o más probablemente en respuestas contrarrevolucionarias. Por otra parte, un proceso de cambio fundamental no es esencial en sociedades más desarrolladas, donde el orden

21 Juan J. Linz, "Political Regimes and Respect for Human Rights: Historical and Cross National Perspectives", en Bernt Hagtved (ed.), Simposio sobre los Derechos Humanos (Oslo: Instituto Nobel, 1988). 
socioeconómico disfruta de una cierta legitimidad y las políticas moderadas no alienarían a la gente respecto al nuevo régimen, en el que las ganancias en libertad personal y política se pueden valorar positivamente por sí mismas.

Todo régimen, y las nuevas democracias no son una excepción, es probable que tenga que enfrentarse con crisis y amenazas de quiebra, pero es importante mantener separados analíticamente el problema de la consolidación del régimen y el de su actuación, sus problemas y sus crisis. Después del establecimiento de una nueva democracia, hay una tentación obvia de atribuir cualquier dificultad seria al legado del pasado, al persistente apego de algunos sectores de la sociedad al régimen autoritario, a la identificación de ciertos intereses con ese régimen y a empezar un debate sobre en qué grado las diferentes decisiones tomadas durante el período de transición hubieran impedido la aparición de esos problemas en fecha posterior. Argumentar que la transición no se ha completado, que la consolidación no se ha logrado, o ni siquiera ha comenzado, es una tentación muy grande dada su conveniencia política para los nuevos líderes que se enfrentan a tiempos difíciles. Al proporcionarles una especie de coartada política, serían exonerados de la responsabilidad por sus propios fracasos o por crear problemas que no era necesario originar, y, además, les ofrecería una especie de cabeza de turco, en vez de obligarlos a hacer un análisis serio de sus propias acciones. Aunque es difícil decidir hasta qué punto las crisis de postransición de los regímenes democráticos han de atribuirse al legado del pasado o a las actuaciones del nuevo régimen y de sus líderes, hacer esta distinción no sólo es intelectualmente importante, sino también políticamente significativo.

La realidad de la transición y las percepciones de la misma, a veces incluso las percepciones erróneas de lo que sucedió o de lo que pudo haber sucedido, se convierten en parte de la realidad política en ese constante proceso de crear regímenes democráticos estables. Las nuevas sociedades democráticas no deberían olvidar sus pasados autoritarios ni las dificultades de la transición y la consolidación. Más aún, sus líderes deberían ser lo suficientemente responsables como para dirigir un debate político que reconociera que un futuro político estable es posible y es responsabilidad de los ciudadanos que gozan de derechos y responsabilidades bajo un gobierno democrático.

Debería subrayarse que un gobierno democrático que tiene suficiente apoyo y legitimidad política es capaz de sobrevivir a una considerable ineficacia en el sistema económico y en la actuación social. La evidencia histórica y datos fiables de gran cantidad de estudios indican que el nivel de legitimidad de la democracia no se ve afectado por el nivel de insatisfacción con la actuación del gobierno. La depresión mundial que presumiblemente destruyó la democracia en la República de Weimar y en Austria creó más desempleo en Noruega y en Holanda, y de hecho consolidó la democracia 
en Noruega y el gobierno holandés fue uno de los más duraderos después de la depresión. El grado de legitimidad institucional fue más decisivo que la crisis económica ${ }^{22}$.

Esto no quiere decir que a medio o a largo plazo la ineficacia del gobierno no perjudique probablemente a la democracia. A corto plazo, sin embargo, una democracia gana un margen de tiempo si no promete que resolverá todos los problemas y, en su lugar, admite que los problemas no se pueden resolver inmediatamente, convence a la gente de este hecho, soluciona el problema de los derechos humanos y la libertad y mantiene un grado de honestidad. Además, un mecanismo interesante de la democracia es que los que están en el poder pueden perder las siguientes elecciones. Si hay instituciones democráticas legítimas, una vez sucedidos los cambios en la administración, normalmente quedan ocho años para sobrevivir a tales crisis. Por tanto, en muchos países el desafío mayor es cómo y bajo qué circunstancias se pueden crear instituciones democráticas legítimas.

\section{CONCLUSION}

En los años setenta tenía sentido decir que la apuesta más segura sobre el régimen que un país tendría en la siguiente generación era que sería algo diferente, pero no radicalmente diferente, de lo que era entonces. En los noventa, podría decirse que en muchos países la apuesta más segura es decir que será una democracia. Este cuadro optimista se ve, no obstante, oscurecido por el hecho de que muy pocas de las democracias recientes están cerca de haberse consolidado, que en muchos casos su actividad está constreñida por la considerable autonomía política de las fuerzas armadas y que se enfrentan a la imposibilidad de satisfacer los deseos de justicia después de años de violación de los derechos humanos básicos. Además, tanto en América Latina como posiblemente en Europa oriental, las democracias se enfrentan a problemas económicos, y consecuentemente sociales, casi irresolubles.

A pesar de todo, la experiencia de los países europeos durante la depresión, incluyendo alguna de las nuevas democracias de Europa, y la de la reciente crisis económica, sugiere que los regímenes democtáticos legítimos pueden sobrevivir, al menos durante algún tiempo, a fracasos considerables de eficacia. No puede excluirse, sin embargo, que un continuo fracaso en la actuación, especialmente después del relevo del partido gobernante, podría llevar a que se le eche la culpa al sistema y sirva de banderín de enganche

22 Juan J. LINZ y Alfred STEPAN, «Political Crafting of democratic Consolidation or Destruction: European and South American Comparisons", en Robert A. Pastor (ed.), Democracy in the Americas: Stoping the Pendulum (Nueva York: Holmes and Meier, 1984), pp. 41-61. 
de una oposición antidemocrática desleal, de tentación para una intervención militar o, en algunos casos, para una continua agitación y desilusión. La ausencia de ideologías alternativas a la democracia hace menos probable su derrocamiento, pero no excluye la pérdida de apoyo, la violencia y la crisis recurrente. En el futuro nos encontraremos algunas democracias asediadas o difíciles, de las cuales Filipinas es hoy un ejemplo.

Mucho depende del liderazgo de las nuevas democracias. Los líderes deben convencer a las gentes del valor de las libertades recobradas, de la seguridad frente al poder arbitrario y de la posibilidad de cambiar pacíficamente de gobierno; y al mismo tiempo deben comunicarles la imposibilidad de superar en un plazo corto el catastrófico legado de los gobernantes no democráticos y de la acumulación de errores que han llevado o han contribuido a la presente crisis. Los líderes tienen la dura y poco grata tarea de decir al pueblo que con la democracia la economía no mejorará inmediatamente; que sin cambio económico no se logrará el cambio social ni la justicia, aunque sean posibles algunas mejoras; y que, en último término, el éxito de una sociedad no es resultado de las actividades del estado, ni siquiera del mejor gobierno posible, sino de los esfuerzos de la sociedad en su conjunto. Los líderes democráticos deben evitar el peligro de hacer una propaganda excesiva de la democracia. Su tarea consiste en rebajar las expectativas al tiempo que mantienen la esperanza en que una sociedad liberada del poder arbitrario podría desarrollarse autónomamente en libertad.

Este artículo resume un trabajo de investigación más extenso titulado "Transition to Democracy: A Comparative Perspective", preparado para la Mesa Redonda de la International Political Science Association en Tokio, 29 de marzo-1 de abril de 1982.

(Traducción: T. GONZÁLEZ DE LA FÉ) 